\title{
EFFECT OF TEMPERATURE AND HUMIDITY ON THE SPREAD AND CHARACTER OF COVID-19
}

\author{
Arkadip Basu \\ Department of Computer Science and Engineering \\ University of Engineering and Management, Kolkata, West Bengal, India
}

\begin{abstract}
The sudden outbreak of COVID-19 as pandemic affected people at large and resulted in a high mortality rate throughout the world by the dreadful Severe Acute Respiratory Syndrome Coronavirus-2 (SARS-COV-2).There are no proper supporting reports for the temperature having a vital role in the transmission of COVID-19 but certain statistics showed some amount of correlation as the present study provided certain statistical evidences on the temperature and location affecting the mortality rates associated with COVID-19. The spread of pandemic and the course of virulence showed its variation on the effect of temperature and irradiance. The study depicted that the mortality rates were lower for the places having the mean temperature greater than $14^{\circ} \mathrm{C}$. The study also observed that to some extent the temperature has its significant impact in the transmission of the virus and the study brings forth that the countries possessing lower temperature should develop stringent policies for controlling the spread of pandemic.
\end{abstract}

Keywords-COVID-19, pandemic, temperature, spread

\section{INTRODUCTION}

Seasonal Influenza-Like-Illness epidemics usually make a significant contribution to the world, especially in the Countries where temperature remains very low during the winter seasons, but such effect is not visualized in those areas where very cool climate do not persists. It has been observed that the Countries like Italy, Germany, France, United States of America, Canada, Iran etc got suffered from InfluenzaLike-Illness in the earlier years. But it is remarkable to note that the Countries like India, Singapore, Thailand, Sri Lanka, Bangladesh, Maldives, U.A.E in the Asian Region, South Africa, Nigeria, Uganda, Kenya and Algeria in African Region and Brazil, Venezuela, Mexico, Argentina in the South American Region as well as in the Southern parts of the America i.e. Texas, Louisiana, New Mexico, Mississippi, Arizona, Los Angeles, etc where the temperature do not fall in such a low manner in the winter season in comparison with the European cooler Regions as well as the North American Regions, did not seem to have been observed similar epidemicity of the Flu-Like-Illness in the earlier years. These regions may have a protective characteristic against COVID19. There may be a low share of elderly population and the high temperatures and humidity all these appear to have helped these areas to escape from the pandemic COVID-19.

This year an outburst has been caused by an infectious disease caused by severe acute respiratory syndrome Coronavirus -2 (SARS-CoV-2). The disease was first identified in December 2019 in Wuhan, the capital of China's Hubei province, and has spread globally. The new virus appears to be very contagious and has shown its ability to spread globally very quickly. In the meeting held on $30^{\text {th }}$ January,2020, per the International Health Regulations (IHR,2005), the outbreak had been declared by the WHO, a Public Health Emergency of International Concern (PHEIC) considering the fact that it had already spread to 18 Countries and a report has been received with regard to human to human transmission. On $28^{\text {th }}$ February 2020,WHO declared the threat to the coivid-19 to "Very High" and Coronavirus 2019-2020 resulted in ongoing pandemic. The virus is stated to have been propagated through people during close contact, often via small droplets produced by coughing, sneezing or talking. The epidemicity of COVID19 was analyzed to correlate the impact of temperature on the mutability of the viral strain.

The comparative studies on the symptoms and the mortality rates of COVID-19 to understand its virulence in the colder continents/countries vis-à-vis the comparatively hotter continents/countries. The COVID-19 has incubation time of 214 days after exposure. The symptoms comprises of fever, cough and shortness of breath or difficulty in breathing. In addition to these reported pateients are often found have symptoms like tiredness, aches, runny nose, sore throat, headache, diarrhoea and vomiting. Some reported cases has also suffered from loss of smell or taste or both. The severity of COVID-19 Symptoms has been found to be very mild to severe, although some people may also be asymptomatic.

A study has been conducted by a group of scientists Jingyuan Wang, Ke Tang,Kai Feng and Weifeng Lv et.al(2020) of the School of Computer Science and Engineering Beihang University, Beijing, China, School of Social Sciences Tesinghua University, Beijing, China and published on $6^{\text {th }}$ April,2020,]where reduction of transmission of Covid-19 has been studied with respect to high temperature and high humidity. The research observation depicted that high temperature and relative humidity may reduce the transmission of COVID-19 both with $1 \%$ significance level. High temperature and humidity may reduce the transmission 
of influenza. The influenza virus were more stable in cold temperature as it can remain active for longer period of time in dry air. The cold and dry weather make our immunity system weaken and more susceptible to the virus. The above mechanisms if applicable to the COVID-19 transmission then the high temperature and high humidity seems to have played

\section{MATERIAL AND METHOD}

The data analysis was performed for the period between 14.04.2020 to 20.04.2020 to obtain a comparison between the virulence of the COVID-19 between hotter region VS the cooler region:

We have considered the following cold Continents/Countries under the Heading ' $\mathrm{A}$ ' and the comparatively hot climatic Continents/Countries under the Heading ' $\mathrm{B}$ '.

$\underline{\text { Table-A }}$

\begin{tabular}{|c|c|}
\hline Sl.No. & Continents/Countries \\
\hline 1 & Europe \\
\hline 2 & North America \\
\hline 3 & China \\
\hline 4 & Iran \\
\hline 5 & Turkey \\
\hline 6 & South Korea \\
\hline 7 & Japan \\
\hline
\end{tabular}

Table-B

\begin{tabular}{|c|c|}
\hline Sl.No. & Continents/Countries \\
\hline 1 & $\begin{array}{c}\text { Comparatively Hotter } \\
\text { Regions of Asia }\end{array}$ \\
\hline 2 & Africa \\
\hline 3 & South America \\
\hline 4 & Oceania \\
\hline
\end{tabular}

\section{DATA FOR 20.04.2020}

20.04.2020

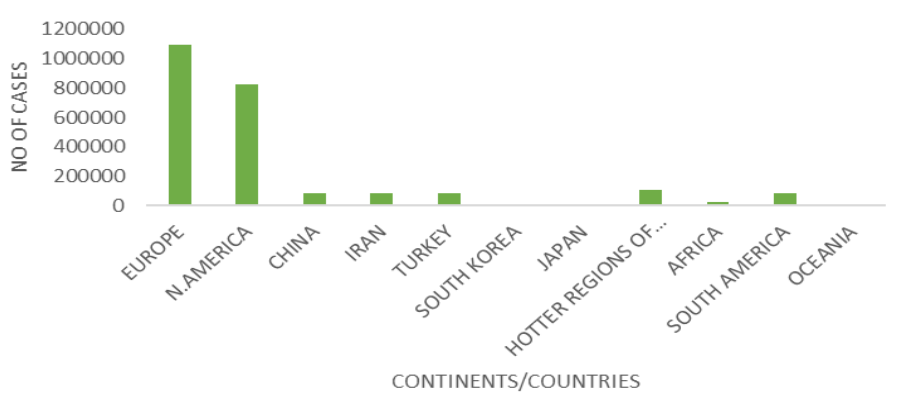

Fig.1.Continent/countries vs No of cases as on 20.04.2020

On calculation of the above data it is presumed that $\mathrm{B}$ is $10.26 \%$ of $A$ and $9.31 \%$ of the total of $(A+B)$

\section{DATA FOR 19.04.2020}

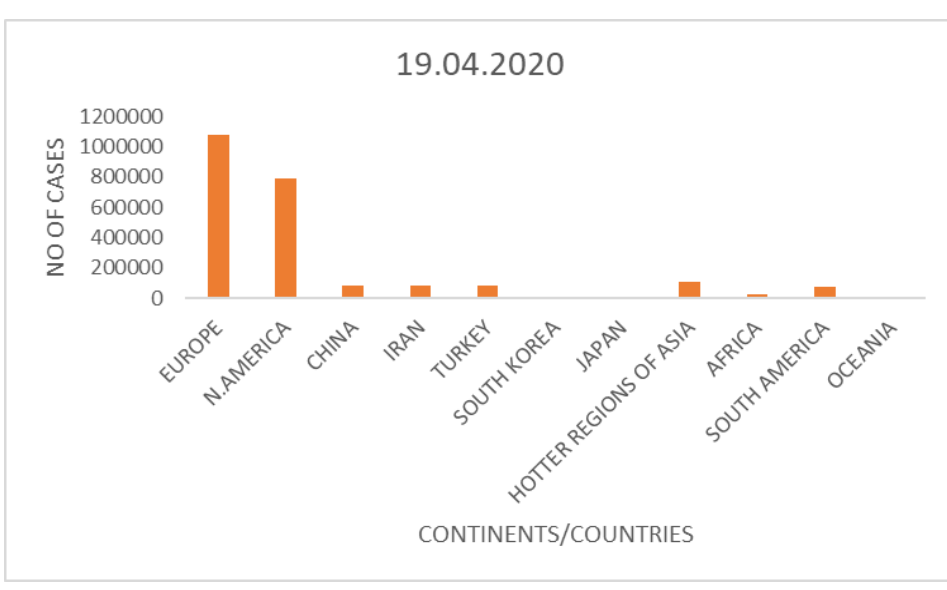

Fig.2.Continent/countries vs No of cases as on 19.04.2020

On calculation of the above data it is presumed that $\mathrm{B}$ is $10.13 \%$ of $A$ and $9.20 \%$ of the total of $(A+B)$

\section{DATA FOR 18.04.2020}

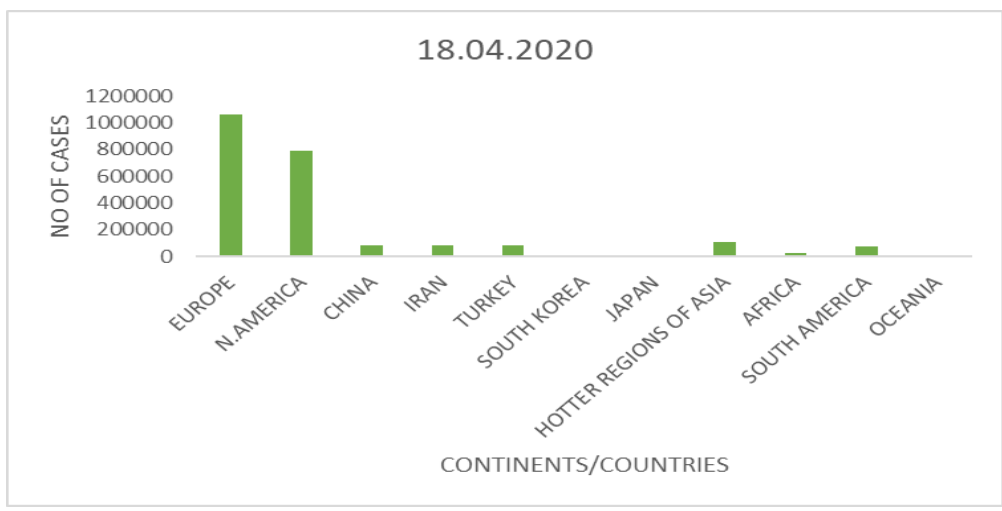

Fig.3.Continent/countries vs No of cases as on 18.04.2020

On calculation of the above data it is presumed that B is $9.96 \%$ of $A$ and $9.09 \%$ of the total of $(A+B)$ 
International Journal of Engineering Applied Sciences and Technology, 2020

Vol. 5, Issue 1, ISSN No. 2455-2143, Pages 228-234

Published Online May 2020 in IJEAST (http://www.ijeast.com)

\section{DATA FOR 17.04.2020}

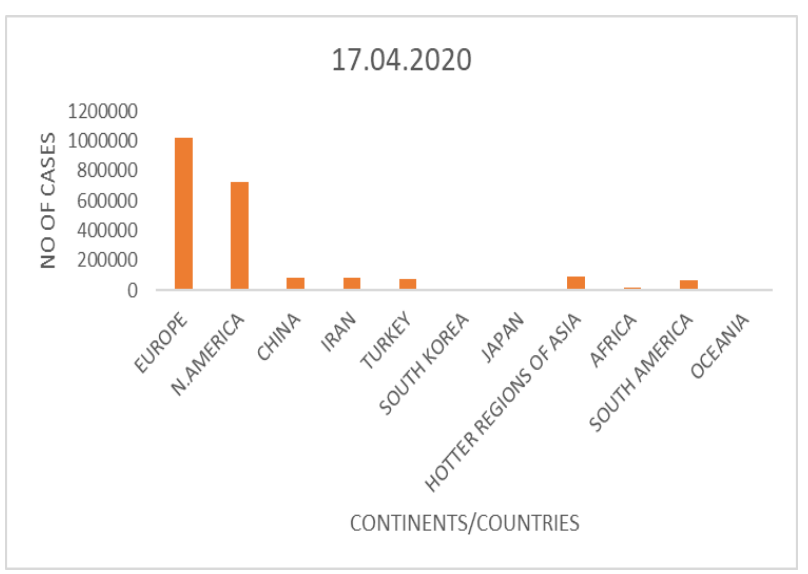

Fig.4.Continent/countries vs No of cases as on 17.04.2020

On calculation of the above data it is presumed that $\mathrm{B}$ is $9.46 \%$ of $A$ and $8.64 \%$ of the total of $(A+B)$.

\section{DATA FOR 16.04.2020}

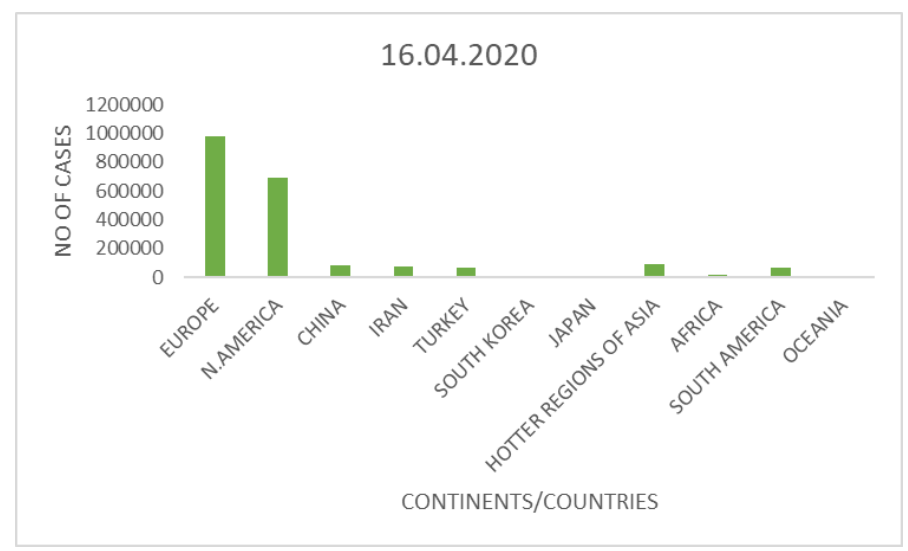

Fig.5.Continent/countries vs No of cases as on 16.04.2020

On calculation of the above data it is presumed that B is $9.27 \%$ of $A$ and $8.49 \%$ of the total of $(A+B)$.

\section{DATA FOR 15.04.2020}

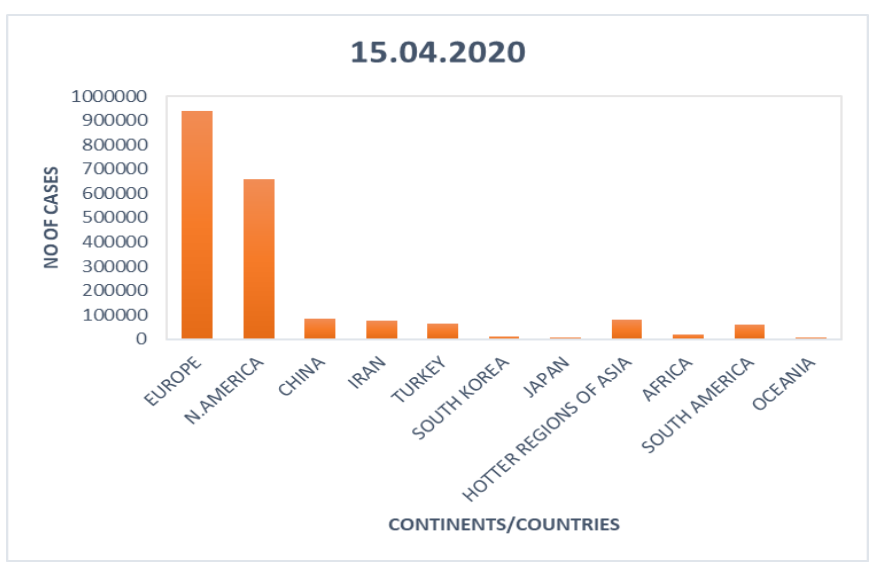

Fig.6.Continent/countries vs No of cases as on 15.04.2020

On calculation of the above data it is presumed that $B$ is $8.95 \%$ of $A$ and $8.21 \%$ of the total of $(A+B)$.

\section{DATA FOR 14.04.2020:}

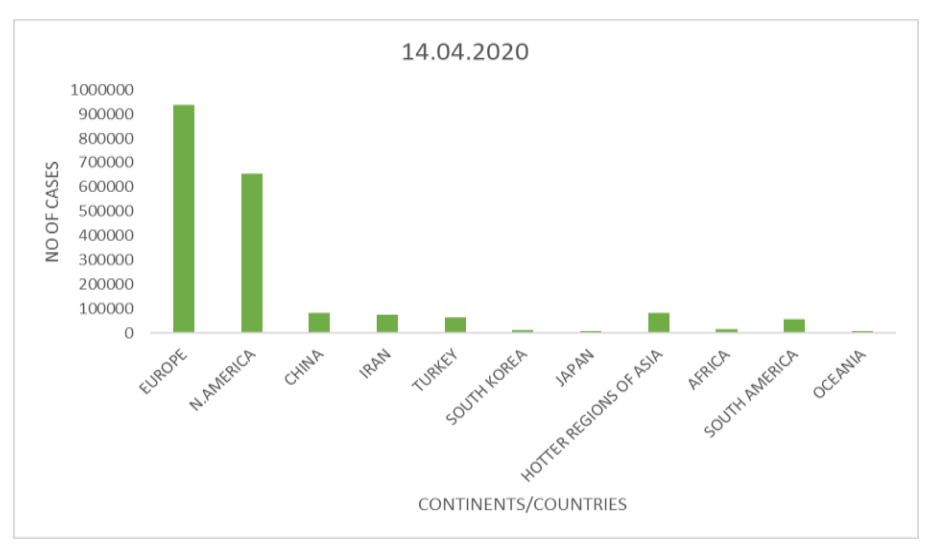

Fig.7.Continent/countries vs No of cases as on 14.04.2020

On calculation of the above data it is presumed that $\mathrm{B}$ is 8.89 $\%$ of $\mathrm{A}$ and $8.16 \%$ of the total of $(\mathrm{A}+\mathrm{B})$. we are unable to furnish any such calculation for the periods earlier than the above due to non-availability of Data.

On translation of the above percentage, it may be inferred that the impact of COVID-19 is comparatively low in terms of its spread and virulence where temperature and absolute humidity are comparatively higher than the cold and humid countries, though there may be some exceptions. To substantiate the fact, a pertinent question with regard to the comparison of population of the countries under the heading A vis-à-vis those under the heading $\mathrm{B}$ requires to be evaluated. We have tried to address the same in the foregoing paragraph.

We would like to compare the population of the countries as shown under the heading $\mathrm{A}$ as well as the same under the heading B: The population of the countries under the heading B is $\mathbf{1 . 6}$ times (approximately) more than the population of the countries under the heading $A$ and instead of such higher population, only ( $9-10) \%$ of the population of the countries under the heading $\mathrm{A}$ in respect of the countries under the heading $\mathrm{B}$ has been affected by the COVID-19. it may, therefore, be presumed that the impact of COVID-19 is comparatively low in terms of its spread and virulence where temperature and absolute humidity are comparatively higher than the cold and humid countries.

In this connection question may be arisen-the countries under the heading $\mathrm{B}$ are not incomparable to the countries under the heading A with regard to testing to detect the actual spread of 
COVID 19 and it may be the actual fact that testing seems to have been made in such extent in the Continents/Countries under the Heading Bas made in the Continents/Countries under the Heading.

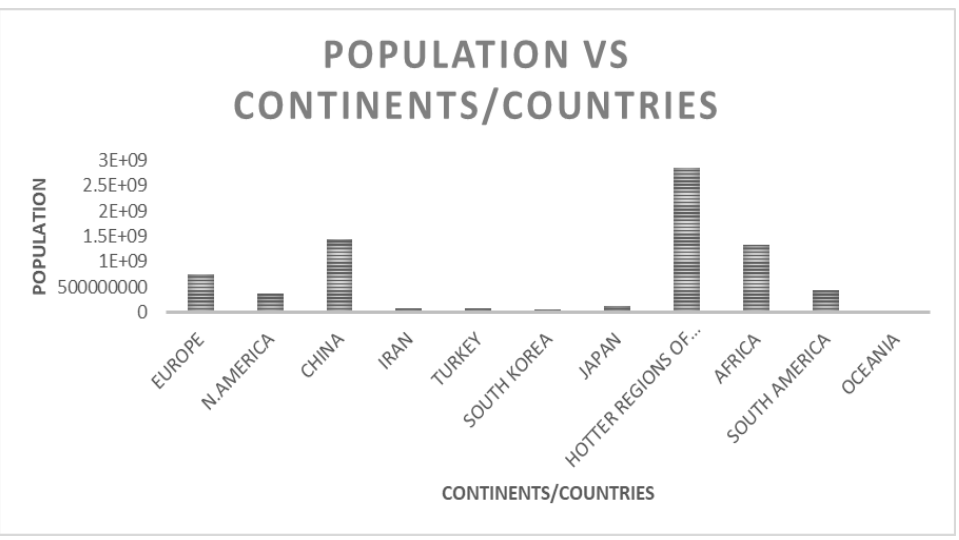

Fig.8.Continent/countries vs Population

A as because the said countries under the heading B do not have adequate infrastructure and resources including financial capacity, although the countries under the heading $\mathrm{B}$ is densely populated. The virulence with regard to mortality rate as well as the transmission ability of the COVID 19 as witnessed in the countries under the heading A, if could be observed in the countries under the heading B, then the hospitals of those countries could be overflooded with patients and there may be vast number of reports from news agencies in this regard. Rather it can be presumed that patients with mostly asymptotic or patients with mild to very mild symptoms seem to have been observed but due to inadequate data the character could not be judged properly at this moments however the Lock-down, social distancing and other measures as recommended by the Governments of those countries must have made substantial impact on the first transmission and Virulence of the COVID 19. It is pertinent to mention that the health care system in the countries under the heading $\mathrm{B}$ are incomparable to the economically advance countries under the heading A although the death rates in the countries under the heading $B$ is much less than the death rate of countries under the heading A. The Dictionary of Epidemiology says that the mortality rate is an 'estimate of the portion of a population that dies during a specified period'[10]. The infection fatality rate is calculated in the following manner:

Infection Fatality Rate $=\underline{\text { Number of Deaths (Numerator) }}$ X 100

Number of people Infected (Denominator)
The virus spread very rapidly i.e. a bigger portion of the general population might have been infected with the virus whether or not they have symptoms, most of the countries instead of counting every infected person, only sick person with potential symptoms and those gone to hospitals or those have a travel history or any other factors have been counted. This means that the figure i.e. the Number of People infected at the denominator may be smaller than what it should actually be although the numerator i.e. the Number of Deaths is almost the actual figure which resulted that the infection fatality rate is higher than it should be and therefore an error would be cropped up. The Asian countries, like India, Bangladesh, Pakistan etc. and the African Countries which have limited resources and limited health care facilities could not determine the actual Number of Infected People and this will lack the correctness of the Infection Fatality Rate. However, we have computed the Fatality Rate of all Countries and is shown in the following Figure:

We have tried to make a study on the Death Rates of both the Continents/Countries on Ist of April and $19^{\text {th }}$ April2020and the same are shown below:

\section{FATALITY RATES OF DIFFERENT COUNTRIES WITHIN A SPECIFIC RANGE}

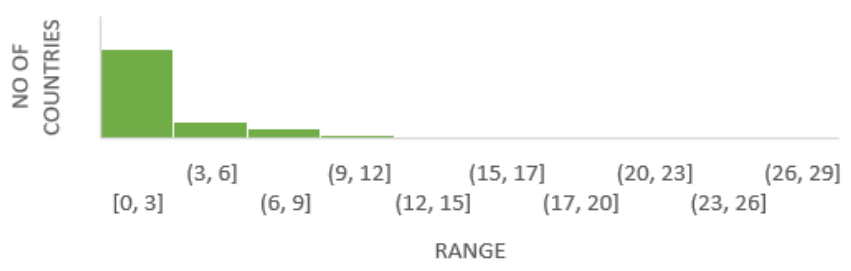

Fig.9. (a)

FATALITY RATE OF DIFFERENT COUNTRIES ON 01.04.2020

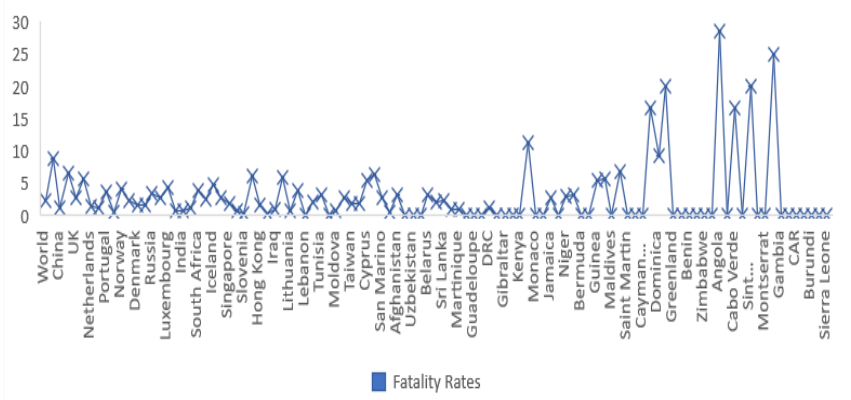

Fig.9. (b)

Fig.9. (a)\&(b): Fatality rate of different countries as on 01.04.2020 
We have tried to make a study on the Death Rates of both the Continents/Countries on Ist of April and $19^{\text {th }}$ April2020.

The actual Fatality Rates may be changed when complete data will be available.

The further researcher shall also analyses in future as to whether the dreadful character of COVID -19 has been subdued in the Continents/Countries under heading B due to the factors of the higher temperature and humidity of those countries by way of practical experiments/after the pandemic will be over.

\section{FATALITY RATES OF DIFFERENT COUNTRIES WITHIN A SPECIFIC RANGE}

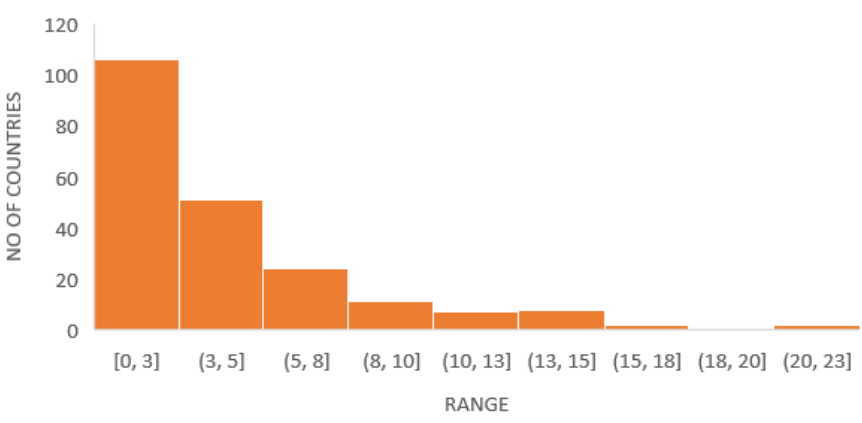

Fig. 10. (a)

\section{FATALITY RATE OF DIFFERENT COUNTRIES ON 19.04.2020}

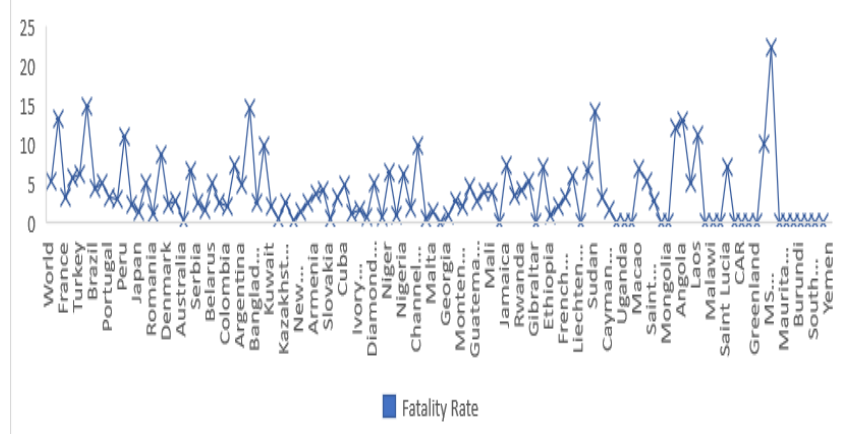

Fig.10. (b)

Fig.10. (a)\&(b): Fatality rate of different countries as on 19.04.2020

Many researchers believe that exposure to cold weather can adversely affect a person's immune response, making it harder for the body to fight off infections. It may be stated that during the winter months people usually get less vitamin $\mathrm{D}$ due to reduced sun exposure. Research suggests that Vitamin D plays the most important role in maintaining the immune system. A 2015 study found that exposing airway cells taken from mice to lower temperatures decreased the immune response of the cells against a mouse adopted rhino virus.

Some research suggests that rhino viruses may replicate more efficiently at temperatures lower that 37 degree Celsius which is the average core body temperature in humans. During cold winter time the temperature inside the nasal cavity gets lowered and is approximately at a temperature of 33 degree Celsius which may make it an ideal breeding ground for rhino viruses.

One study examined as to whether any variations in temperature and humidity let to a higher risk of rhino virus infection. The researchers found that decreases in both body temperature and humidity over a 3 day period increased the risk of rhino virus infections in participates. In the same study researchers found that the majority of infections occurred in temperatures(Celsius) at 0 and below. Another study in Guinea pigs suggests that the ideal temperature for the influenza virus to spread is 5 degree Celsius. The future researchers shall study on the above points in the case of COVID-19, due to insufficient infrastructure and no laboratory accessibility, we could not have made any advancement in this regard.

We know that breathing in cold and dry air causes the blood vessels in the upper respiratory track to narrow in order to conserve heat. This may prevent the white blood cells from reaching the mucous membrane, which makes it harder for the body to fight off germs. We don't know whether the same preconditions are viable in the case of COVID 19 and more researches are required. However, if the above-mentioned factors are considered to be applicable in the case of COVID19 , then the virulent character as well as rapid spreading capacity as found in the colder regions, might have an explanation for the impact of temperature and humidity. It has been observed that most of the COVID-19 infected persons in the regions under the heading $\mathrm{B}$ are either more or less asymptotic or with mid to very mild symptoms, besides the mortality rate is also very low as of $20^{\text {th }}$ April2020, when the paper is being written.

We would like to show a graph of the percentage of elderly persons in both the regions $\mathrm{A}$ and $\mathrm{B}$ and the mortality rate:

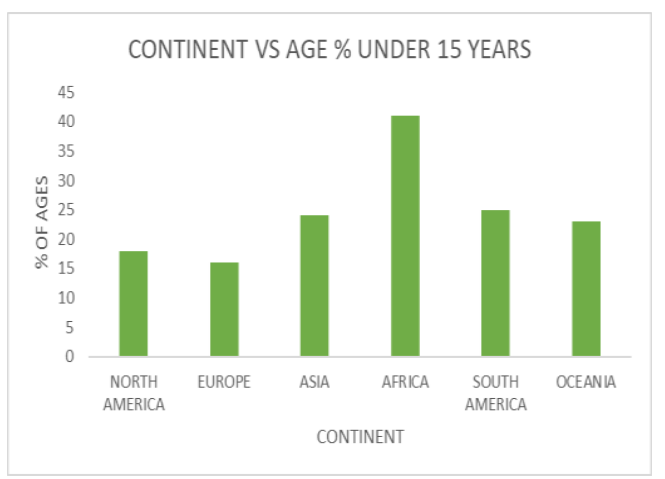


Fig.11.Continent vs \% age over 15 years

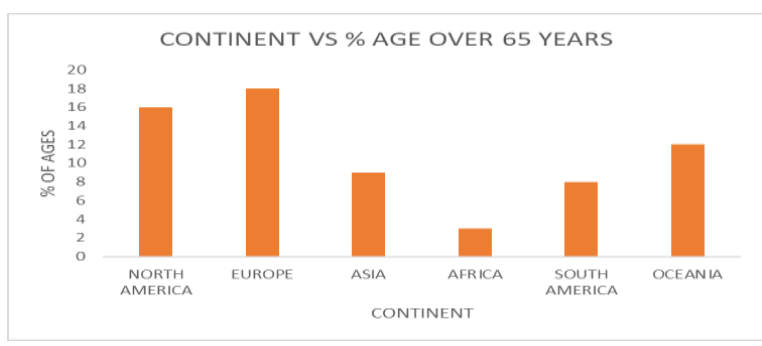

Fig.12.Continent vs $\%$ age over 65 years

The impact of COVID-19 is most on the comparatively higher age groups and thereby a higher mortality has been observed. On analyzing the above two Charts, it appears that higher percentage of age over 65 years is seen in the cold continents in comparison to the relatively hotter regions, though few countries namely China, Iran, Turkey, South Korea and Japan are of temperate climate. This is also perhaps a reason for higher mortality rates in the continents like North America and Europe. The future analysis will reveal further evidences.

In this context, it may be mentioned here that the researchers have observed that the influenza virus transmission is dependent upon humidity and temperature. The transmission is highly efficient at 5 degree centigrade but it gets inefficient at 30 degree centigrade. The dry conditions have also been found to be more favourable for the spread than either intermediate or humid conditions. Having analyzed the Data, we can faintly but not boldly claim that the COVID-19 have shown the similar characteristics by way of change of character through further mutation. However, we are still not confirm to make a commendable comment in this regard. Future research shall surely reveal the fact more prominently.

\section{LIMITATIONS:}

We could not have made our study resting upon the laboratory analysis/accessibility and limited infrastructure. We also don't know how many actual testing for detection of COVID-19 are being made in the countries under the heading B except India, however we made our observation on the basis of analysis of data. We could not have made any study on the particle size distribution of the droplets exhaled by sneeze and the evaporation effects of the droplet, the differences of biological dynamic mechanism and characteristics between sneeze and other respiratory activities due to higher temperature and humidity. A study on that effect was conducted by J.Y.Han, W.G.Weng and Q.Y.Huang,Department of Physics, Institute of Public Safety Research, Tsinghua University,Beijing.,People's Republic of China(https://royalsocietypublishing.org/doi/full/10.1098/rsif. 2013.0560). Accordingly, the observation made by us is subject to error.

\section{CONCLUSION}

Having analysed the aforementioned facts we think that the countries in Asia where temperature is relatively higher in the winter time as well as South America, Africa and Oceania where temperatures are relatively higher have started showing increase in the number of COVID-19 cases but we are of the view that no exponential growth rate might not have been surged rather we feel the warmth and humid weather might have an impact on the growth as well as the virulence character of COVID-19. We hope and trust that the COVID19 may turn to be a endemic within the coming 4-5 months.

\section{RESULTS AND DISCUSSION}

The virulence and the spreading capacity of Corona virus i.e. COVID-19 appears to be weaker in countries which are more exposed to sunlight with warmer temperature and heat. The study shows the rate of affected persons in the relatively warmer part of the world i.e. mainly in the warmer countries are much less than the western countries although most of the relatively warmer countries have a significantly high population density. The possibility that the COVID-19 seems to have been mutated further due to the high level of exposed sunlight, its UV Rays as well as the scorch heat resultantly showing a lesser virulence in its character and its lesser in its spreading capacity in the community and this seems to have been manifested while we move from colder climatic countries to the relatively hotter climatic countries of the world. It may also be stated here that there is also factors like lesser number of testing which shows detection of lesser number of infected persons but the requirement of hospitalisation seems to have neither been visualised nor the healthcare system is seen to be overwhelmed. The countries like Singapore or Thailand etc can also be considered where rate of affected person is more and this is due to increase in number of tourists. A possibility is also there that the corona virus may survive for lesser time while it is more exposed to heat and sunlight.

A possibility is there that corona virus has much similarity with the character of seasonal influenza, whose affect, spread or rate of mortality is much more in the colder region than the warmer region. As the virus i.e. COVID-19 is a new virus, it is practically impossible to predict at this moment to make any final comment and we are looking forward that future research will surely reveal many more facts about the COVID-19.

\section{ACKNOWLEDGEMENT}

This research paper has been prepared by me with the help of my University. I would like to acknowledge all the Doctors, Workers, Scientist, and all other people who are working day and night to rescue the world from this pandemic situation. My parents have provided an immense mental strength during this work. Thus, I am thankful to all of them. 


\section{REFERENCE}

1. Lowen Anice C, Steel John,'Roles of Humidity and Temperature in Shaping Influenza Seasonality", Journal of Virology, June 182014.

2. Bukhari Qasim, Jameel Yusuf, "Will Coronavirus Pandemic Diminished by Summer?", Social Search Research Network,19 Mar 2020.

3. Oliva JESUS, CONCEPCIÓN DELGADO-SANZ, LARRAURI AMPARO, "ESTIMATING THE BURDEN OF SEASONAL INFLUENZA IN SPAIN FROM SURVEILLANCE OF MILD AND SEVERE INFLUENZA DISEASE, 2010-2016" , INFLUENZA OTHER RESPIR VIRUSES. 2018 JAN; 12(1): 161-170,2017 DEC 15

4. Huang ChaOlin, Wang Yeming, Li Xingwang, Ren Lili, ZHAO JiANPING, Hu Yi, ZHANG LI, FAN GuOHUI, XU JiUYANG, GU XiAOYING, Cheng Zhenshun, Yu Ting, Xia JiaAn, WeI Yuan, Wu Wenjuan, Xie Xuelei, Yin Wen, Li Hui, LiU Min, XiaO Yan, Gao Hong, GuO Li, Xie Jungang, Wang Guangfa, JiAng Rongmeng, GaO Zhancheng, Jin Qi ${ }^{4}$, Wang JiANWEI, CAO Bin, "Clinical Features OF PATIENTS InfeCted With 2019 Novel Coronavirus in Wuhan, ChinA", FEB 2020

5. Novel Coronavirus(2019-nCoV), 28 Jan 2020,WHO

6. Novel Coronavirus(2019-nCoV),29 Jan 2020,WHO

7. Novel Coronavirus(2019-nCoV),30 Jan 2020,WHO

8. Symptoms, Coronavirus Disease 2019, Centers for Disease Control and Prevention

9. Coronavirus disease 2019 (COVID-19), MAYO CLINIC

10. Porta Miquel , A dictionary of Epidemiology", $5^{\text {th }}$ Edition, Oxford University Press

11. Estimated InfluenZa Illnesses, Medical Visits, HOSPITALIZATIONS, AND DEATHS IN THE UNITED STATES - 2018-2019 INFLUENZA SEASON, CENTERS FOR DisEASE CONTROL AND PREVENTION

12. White Matthew D., Bosio Catharine M., Duplantis Barry N., Nato Francis E., " Human body temperature and new approaches to constructing temperature sensitive bacterial vaccines", Cell Mol Life Sci.2011 Sep; 68(18): 3019-3031.
13. Gaunt E. R., Hardie A., Claas E. C. J., Simmonds P, Templeton K. E., "EPidemiology and Clinical Presentations OF THE Four Human CORONAVIRUSES 229E, HKU1, NL63, AND OC43 DETECTED OVER 3 YEARS USING A NOVEL Multiplex Real-Time PCR Method", J Clin Microbiol. 2010 Aug; 48(8): 2940-2947.

14. Cedraschi Christine, Saya Laurence, Klein Patrick, Bordet MARIE-France, CARrat FABrice, "REPRESENTATIONS OF INFLUENZA AND INFLUENZALIKE ILLNESS IN THE COMMUNITY - A QUALITATIVE STUDY", BMC FAM PRACT. 2013; 14: 15

15. Balboni Andrea, Gallina Laura, Palladini Alessandra, Prosperi Santino, ${ }^{1}$ and Battilani Mara, "A Real-Time PCR Assay for Bat SARS-Like Coronavirus Detection and Its Application to Italian Greater Horseshoe Bat Faecal Sample Surveys", The Scientific World Journal, Volume 2012

16. Foxman Ellen F, Storer James A, Fitzgerald MEgan E., Wasik Bethany R, Hou Lin, Zhao hongyu Zhao, Turner Paul E, Pyle Anna MARIE, IWASAKI AKIKO, “TEMPERATURE-DEPENDENT INNATE DEFENSE AGAINST THE COMMON COLD VIRUS LIMITS VIRAL REPLICATION AT WARM TEMPERATURE IN MOUSE AIRWAY CELLS", PROC NATL ACAD SCI U S A. 2015 JAN 20; $112(3)$ : 827-832.

17. YANG WAN AND MARR LINSEY C., "DYNAMICS OF AIRBORNE INFLUENZA A VIRUSES INDOORS AND DEPENDENCE ON HuMidity", PLOS ONE. 2011; 6(6): E21481.

18. Wang Jingyuang, TANG Ke, Fend Kai, Lv WeIfEng, " High Temperature and High Humidity Reduce THE TRANSMISSION OF COVID-19”, SSRN

19. IKÄHEIMO TIINA M, JAAKKOLA KARI, JOKELAINEN JARI, SAUKKORIIPI ANNIKA, ROIVAINEN MERJA, JUVONEN RAIJA, VAINIO OLli, JAAKKOLA JOUNI J.K., "A DECREASE IN TEMPERATURE AND HuMidity PRECEDES Human RHINOVIRUS INFECTIONS IN A COLD Climate", VirUSES. 2016 SEP; 8(9): 244.

20. “OUT IN THE COLD”,HARVARD HEALTH PUBLISHING,JANUARY 2010

21. Transmission of COVID-19”, Social Search Research Network, $6^{\text {th }}$ April,2020. 